\title{
Classroom intervention to change peers' attitudes towards children who stutter: A feasibility study
}

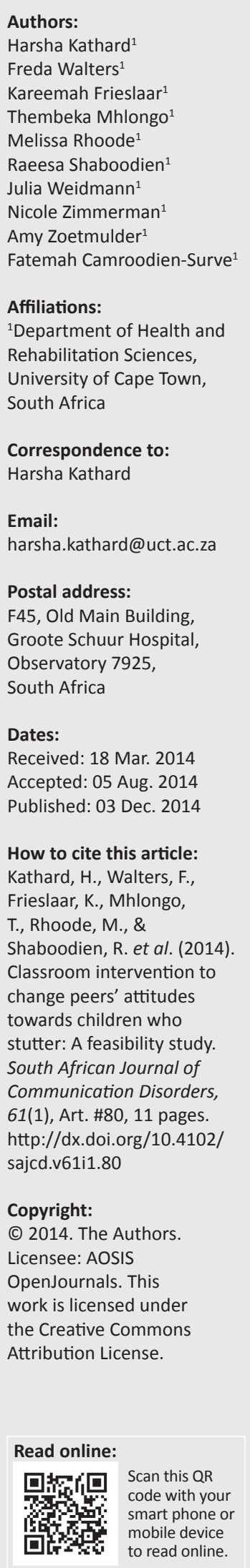

Background: Before interventions are implemented, the potential treatment benefit must be determined.

Objectives: The primary objective of this feasibility study was to assess if peers' attitudes towards children who stutter (CWS) change one month after the administration of the Classroom Communication Resource (CCR). The secondary objectives of the study were to determine if differences in peer attitudes were related to gender and to previous exposure to a person who stutters.

Method: The study used a cluster randomised control trial design. The study included 211 Grade 7 participants from schools in the Cape Town Metropole. The CCR intervention was administered to 97 participants in the experimental group, whilst 114 participants in the control group did not receive the intervention. The Stuttering Resource Outcome Measure (SROM) used as the outcome measure during pre- and post-test period. STATISTICA was used for in-depth data analysis.

Results: An overall positive direction of change in scores was observed for the experimental group compared with the control group. However, the magnitude of change in the experimental group was not statistically significant $(p=0.2683)$. Male and female participants did not differ significantly in their scores on the SROM across pre-test and post-test periods. Participants who had exposure to individuals who stutter had significantly more positive scores on the SROM in the pre-test and post-test periods compared to those who had no direct exposure to stuttering.

Conclusion: This result indicated the beginning of positive attitude change which may be attributed to the intervention. Further investigation is warranted.

\section{Introduction}

Social interactions and associations with peers are important for learners who are typically between 10 and 13 years. (Evans, Healey, Kawai et al., 2008; Parker \& Asher, 1993). They are under pressure by peers to conform to group norms, particularly for those individuals who differ beyond what is considered 'acceptable' (Evans et al., 2008), predisposing them to teasing and bullying. Whilst bullying is regarded as the use of force and emotional, verbal and/or physical abuse to coerce another, teasing is viewed as a lighter form of bullying and refers to mocking or provoking an individual in a playful but hurtful manner (Langevin, 1997). In the short-term, teasing and bullying may lead to low self-esteem and low self-confidence (Liang, Flisher \& Lombard, 2007) of victims and can also lead to negative long-term psychological, emotional, physical and social consequences (Langevin, 2009).

Communication disorders such as stuttering are often not viewed as 'acceptable' individual differences (Murphy \& Quesal, 2002). Children who stutter (CWS) are perceived to be shy, less extroverted and less popular compared to their peers. (Evans et al., 2008). Peers feel that CWS are 'less competent' than those who speak more fluently (Dietrich, Jensen \& Williams, 2001). As a consequence of these negative attitudes held by peers, CWS have been found to be at greater risk of being teased and bullied compared to their fluent peers (Turnbull, 2006; Hughes, 2014). The overall incidence of bullying in primary school learners in the United States of America (USA) lies between $49 \%$ and 58\%; however, this incidence increases to $81 \%$ for CWS (Murphy, Yaruss \& Quesal, 2007). In South African schools teasing and bullying is a widespread problem of increasing concern (Mestry, Van der Merwe \& Squelch, 2006). Consultation with teachers in the Western Cape indicated that teasing and bullying of CWS was a common problem and they requested support (Filies, Hartley, Kaplan \& Pettit, 2009). As part of a comprehensive approach to intervention which considers the individual and his or her environment, speechlanguage therapists (SLTs) therefore must consider interventions aimed at improving attitudes 
of peers towards CWS as a strategy for minimising teasing and bullying (Yaruss, 2007). One strategy is classroom-based intervention aimed at improving peers' attitudes to CWS.

The teasing and bullying: unacceptable behaviour (TAB) programme was one of the first formal classroom-based interventions to be developed in Canada. The intervention comprises of a 14-minute video and six units of classroombased lessons originally designed for Grade 4-6 learners, with the biggest impact occurring in the fourth grade (Langevin, 2000). This resource can be used on its own in classrooms or as part of anti-bully campaigns across the school, as well as in individual counselling The TAB was not found to be suitable for the South African context, given its length and socio-cultural relevance. In response, a new intervention - classroom communication resource (CCR) - was developed in South Africa. Development of the CCR began in 2009 which gathered teacher and learner responses to the classroom resource aimed at improving peers attitudes to CWS (Filies et al., 2009). Further studies revised and refined the CCR (Badroodien et al., 2011; De Grass et al., 2010; De Freitas, Geben, Parusnath, Relleen, \& Van den Berg, 2012) into its current form. The intervention was found to be better suited to Grade 7 learners because teasing was also prevalent during this grade and they had developed literacy and comprehension skills in English to benefit from the intervention. The intervention requires that teachers are provided with education on stuttering and on the purpose and administration of the intervention. The learners are directly involved in the intervention via a story and role-play. Thereafter, the teacher and learners discuss the issues which commonly include understanding stuttering, difference, diversity, prejudice, teasing, bullying and social inclusion. The intervention targets three domains of attitude change viz. positive social distance, verbal interaction and social pressure. Teachers are required to reinforce the learning related to the intervention as part of regular classroom activities. In order to investigate the effect of the CCR on peer attitudes towards CWS, an outcomes measure called the 'stuttering resource outcomes measure' (SROM) was developed and validated (Walters, 2014).

However, before a new intervention is adopted, it is imperative that it is assessed for potential benefit as part of a feasibility study (Thabane, et al., 2010). The main objective of this study was to ascertain if there was potential treatment benefit of the CCR intervention in improving peers' attitudes towards CWS one month post-intervention. A further study currently in progress will examine the treatment benefits at 6 months post-intervention. Together, these studies will inform the feasibility of a larger randomised control trial (RCT).

There is a dearth of studies which assess the benefits of classroom interventions for stuttering. The literature available in this area is mainly on the TAB and its development. A recent study by Langevin and Prasad (2012) was the only study to determine the treatment benefit of the TAB, a classroom-based intervention. They used a pre-test/post-test design to measure attitude changes 3-4 week post-intervention. They reported significant differences between pre- and post-test scores on their outcomes measure, the 'peer attitudes toward children who stutter' (PATCS) scale. These results suggested that the TAB may be effective in improving peer attitudes towards CWS. Initial positive changes were observed during the initial period 3-4 weeks post-intervention. (Langevin \& Prasad, 2012). Nonetheless, it appears important to address attitudes over an extended period of time to effect real change (Whitehead, 2001). It is also possible that attitudes may not shift or perhaps worsen when learners do not respond positively. Therefore, it is critical to determine the direction of change as a way of assessing the intervention effect. The magnitude of change is also useful to observe. However, because this study is examining change at one month post-intervention, the magnitude of change may not be clearly evident.

Historically, research suggests that gender may influence peer attitudes towards CWS. However these results have been inconclusive (Wiesel \& Spektor, 1998; Dietrich et al., 2001; Langevin, Kleitman, Packman et al., 2009). More recently, St. Louis (2012) also confirmed that research on the influence of gender on peers' attitudes towards stuttering was inconclusive. As a secondary objective this study therefore examines how male and female participants compare in their attitudes towards CWS before and after intervention.

A further secondary objective of this study is to ascertain how individuals who are exposed to stuttering compare to those who do not have direct exposure. Langevin \& Hagler (2004) reported that children with no prior exposure to stuttering typically have less positive attitudes compared to their peers who have exposure. This study adds to the limited body of literature on the issue of exposure and attitude change.

\section{Methodology \\ Objectives}

\section{Primary objective}

To determine if participants' attitudes towards CWS change in direction and magnitude one month after the administration of the Classroom Communication Resource (CCR) intervention.

\section{Secondary objectives}

1. To determine if the changes in attitudes were influenced by the participants' gender.

2. To determine if the changes in attitudes were influenced by the participants' previous exposure to a person who stutters.

\section{Study design}

This study used a cluster randomised control trial design. This design allows for identification of cause and effect relationships within a controlled environment (Leedy \& Ormrod, 2005), whilst striving for equivalence of groups prior to implementation of the intervention (Lindegger, 2006). As this was a preliminary study to assess potential benefit 
of the intervention, the sample size could not be exactly calculated given that the cluster effect was not known at this stage of the study. Therefore, whilst the design elements were aligned with that of a randomised control trial, it was not the intention of the study to make conclusive statements about whether the treatment effects were significant or not. Instead, the intention was to observe the potential treatment effect. The stuttering resource outcomes measure (SROM) was administered to both the experimental and control groups pre- and post-intervention. The intervention, the classroom communication resource (CCR) was only administered to the experimental group, as suggested by Creswell (2009), whilst the control group did not receive the intervention during the study period.

\section{Participants}

In South Africa, schools fall within five (5) quintiles based on the National Poverty Distribution Table, with quintile 1 representing the lowest socio-economic strata and quintile 5 the highest (Department of Education, 2008). Whilst this study drew learners from quintiles 2 and 3 (lower quintiles), the larger study drew learners from the remaining quintiles so that the overall sample was drawn from across school quintiles.

\section{Inclusion criteria}

The participants were required to be Grade 7 learners, in mixed gender classes from English dual-medium schools in Cape Town, falling within quintiles 2 and 3 on the National Poverty Distribution Table. Learners were also required to have adequate English literacy skills to complete the questionnaire, the SROM.

\section{Exclusion criteria}

Learners from schools that had on-site speech therapy services and learners from schools that have previously participated in similar studies (prior to 2013) were not included in the study.

\section{Sample size}

According to Lenth (2001), a sample of sufficient size is necessary to yield statistical significance in randomised control trials. However, given that this was an initial study, the sample size estimate was based on the number of participants who could be recruited into the study within the capacity of the research team. The intention was to recruit a sample size that would exceed 192 participants, a sample size which would be larger than previous undergraduate studies. This rationale was informed by the mean observed difference between the experimental and control groups in the studies which developed the CCR.

Using this power analysis as a guideline, this study recruited 211 participants, with 97 in the experimental and 114 in the control group. Of this total sample, 108 were males and 103 were females. The majority of participants (197) reported to have been previously exposed to people who stutter, whilst 44 reported no previous exposure. The average age of participants was 13 years.

Cluster randomisation design was applied with schools as the unit of cluster. A list of all the schools in Cape Town was obtained from the Western Cape Education Department (WCED). From this list, only those schools that fell within quintiles 2 and 3 on the National Poverty Distribution Table and those that were English dual-medium were considered part of the sampling cluster. Three schools (Schools A, B and $C$ ) were randomly selected and randomised to either the experimental or control group. Although the classrooms were used as the unit of intervention, it was necessary to randomise schools rather that classrooms to prevent contamination effect (Lindegger, 2006). Two schools were assigned to the experimental group, whilst the control group comprised of one school. From these schools, the necessary sample size of participants that met the selection criteria was able to be obtained.

\section{Method of recruitment}

Three schools were contacted telephonically and then in person to invite them to participate in this study. Written permission from the principals and grade teachers was obtained. Informed consent was obtained from the participants' parents and assent was attained from the participants themselves.

\section{Research instruments and their validity and reliability}

Stuttering Resource Outcomes Measure (SROM): The SROM is a questionnaire based on the PATCS. It measures peer attitudes toward children who stutter through the use of a five-point Likert scale. The original 36 items of the PATCS were reduced to 20 items in order to decrease the amount of time needed for administration (Badroodien et al., 2011; De Freitas et al., 2012; De Grass et al., 2010). The 20 test items have been selected and adapted to be an accurate reflection of the three content areas of the PATCS ('positive social distance', 'social pressure' and 'verbal interactions'; Langevin, 2009). 'Positive social distance' is defined as the general degree of acceptance or comfort peers display in the presence of CWS; 'Social Pressure' is concerned with what peers think about CWS; and 'verbal interaction' taps into aspects of frustration or annoyance through interaction with CWS (Langevin, 2009). In addition, the items were culturally and linguistically adapted to the South African context. This validated measure (Walters, 2014) was used in this study.

Classroom Communication Resource (CCR): The CCR is a classroom-based stuttering resource. It aims to increase peers' awareness about communication disorders, stuttering in particular, as well as to improve negative attitudes. The revised CCR consists of two parts. In the first part, information is provided to teachers to explain the nature of stuttering and the aim of the resource as well as guidelines on how to manage a child who stutters in the classroom. The second part of the CCR outlines the administration guidelines and contains the actual classroom resources, namely a social 
story, a role play and class activities and discussions. This revised intervention tool was used in the current study.

\section{Ethical considerations}

Prior to the study being conducted, permission was obtained from the Faculty of Health Sciences Human Research Ethics Committee and the Western Cape Education Department (WCED). Ethical research ensures that the rights of the participants involved are preserved through the ethical principles of autonomy, confidentiality, beneficence, nonmaleficence and justice, as stated in the Helsinki Declaration (Williams, 2008)

\section{Data collection}

The data-collection process occurred in three phases: Phase 1: Pre-intervention Phase. Both the experimental and the control group were shown a video clip of a child who stutters and provided with a definition of stuttering. In this way, all participants were expected to have an understanding of stuttering as the focus of intervention. Before data collection, the researchers split into two groups for data collection and data analysis. In this way, the researchers who analysed the data could not distinguish between the experimental and control group. This blinding procedure is recommended for randomised control trials, and was thus utilised in this study (Lindegger, 2006). The pre-intervention SROM was then administered to all participants in experiment and control groups by the researchers. Unrelated practice items were provided so that participants could familiarise themselves with completing a questionnaire using the Likert response format. The researchers were available to clarify any questions the participants have regarding their understanding of items. Participants completed the SROM, selecting the responses that were most applicable to them. Prior to the intervention the researchers conducted a thirty-minute training session with the experimental group teachers to discuss the aims and administration of the CCR. Teachers were equipped with the CCR booklet, guidelines on how to use and administer the CCR, as well as strategies to manage stuttering in the classroom.

Phase 2: Intervention Phase. During the intervention phase, the CCR was administered by the grade teachers to the experimental group only. The control group did not receive the CCR during the study period. The researchers observed the administration process so as to ensure that the classes received similar administration of the CCR. Following the administration of the CCR, teachers were reminded about the strategies that could be used to reinforce the discussion based on the SROM to promote positive attitudes during the one month time interval between pre- and post-testing.

Phase 3: Post-intervention Phase. In the post-intervention phase, the SROM was re-administered to both the experimental and the control group one month post administration of the CCR in order to measure changes in attitudes (if any) towards CWS. The researchers furthermore provided teachers with strategies to sustain any positive behavioural changes that might have occurred. Whilst the researchers were aware of the limitations of using the same measure as the post-test measure, there was no equivalent additional measure that was considered suitable. Therefore, the SROM was used as the only outcome measure. A six month follow-up will be conducted on both the experimental and control group. After this, the control group teachers will be trained on administering the CCR and the control group will receive the intervention.

A summary of the research process is in Appendix A and Appendix B.

\section{Analysis of data}

The researchers themselves undertook preliminary analyses of the data, whilst a statistician checked the results and conducted more in-depth analyses. A score was allocated for each response on the SROM, with the response 'strongly disagree' reflecting a score of -2 and the response 'strongly agree' a score of 2 . The response 'not sure' corresponded with a score of 0 . All negatively worded items were reverse scored. The total scores obtained on the SROM were used for data analysis. The minimum total score obtainable was -40 , reflecting a negative attitude, whilst the maximum was 40 , indicating a positive attitude. The reliability in terms of internal consistency of items on the SROM was confirmed using Cronbach's alpha.

Descriptive statistics were used to analyse the SROM total scores in both the pre-test and post-test periods for the experimental and control group participants. In particular, the range, mean and standard deviation of total scores were analysed in terms of differences in mean total scores between groups (experimental vs. control), gender (male vs. female) and exposure (yes vs. no).

Inferential statistics were used to determine the effect of the intervention. For this, the distribution of the total score was assessed both visually on a histogram and by means of the Shapiro-Wilk's test, which evaluates normal distribution of a sample (Panik, 2005). Results were found to be adequately normally distributed. Thus, analysis of variance (ANOVA) was used to determine whether a statistically significant difference in attitudes (as measured by the SROM) was observed between groups (experimental vs. control), gender (male vs. female) and exposure (yes vs. no). However, given the limitations of the sample size, the results cannot be regarded as conclusive (see Table 1, Table 2 and Figure 1).

\section{Results \\ Treatment effect}

The primary objective of this study was to observe if participants' attitudes towards CWS change in direction and magnitude one month after the administration of the Classroom Communication Resource (CCR). During the pre-test, the experimental group had a statistically 
TABLE 1: Total score by group, gender and exposure; pre-test vs. post-test.

\begin{tabular}{|c|c|c|c|c|c|c|c|c|c|c|}
\hline \multirow[t]{2}{*}{ Category } & \multirow[t]{2}{*}{ Test type } & \multirow[t]{2}{*}{$N$} & \multicolumn{4}{|c|}{ Pre-test } & \multicolumn{4}{|c|}{ Post-test } \\
\hline & & & Min. & Max. & Mean $(\chi)$ & Std. dev. $(\sigma)$ & Min. & Max. & Mean $(\chi)$ & Std. dev. $(\sigma)$ \\
\hline \multirow[t]{3}{*}{ Group } & Experimental & 97 & -25 & 40 & 9.51 & 14.10 & -16 & 40 & 12.22 & 13.42 \\
\hline & Control & 114 & -32 & 34 & 7.96 & 11.96 & -21 & 40 & 8.32 & 13.95 \\
\hline & Total & 211 & -32 & 40 & 8.67 & 12.98 & -21 & 40 & 10.11 & 13.81 \\
\hline \multirow[t]{3}{*}{ Gender } & Male & 108 & -32 & 40 & 8.68 & 12.77 & -21 & 40 & 10.55 & 13.97 \\
\hline & Female & 103 & -20 & 40 & 8.67 & 13.26 & -17 & 40 & 9.66 & 13.71 \\
\hline & Total & 211 & -32 & 40 & 8.67 & 12.98 & -21 & 40 & 10.11 & 13.81 \\
\hline \multirow[t]{3}{*}{ Exposure } & Yes & 167 & -32 & 40 & 9.62 & 13.23 & -17 & 40 & 11.47 & 13.71 \\
\hline & No & 44 & -20 & 33 & 5.07 & 11.42 & -21 & 31 & 4.95 & 13.09 \\
\hline & Total & 211 & -32 & 40 & 8.67 & 12.98 & -21 & 40 & 10.11 & 13.81 \\
\hline
\end{tabular}

Min, minimum; Max, maximum; Std. dev., standard deviation

TABLE 2: A summary of the ANOVA results when analysing group, gender and exposure over the pre-test and post-test.

\begin{tabular}{lllll}
\hline Category & Comparisons & $\boldsymbol{d f}$ & $\boldsymbol{F}$-Statistic & $\boldsymbol{p}$-Value \\
\hline Group & Experimental vs. Control & 1 & 4.34 & 0.0379 \\
& Pre-test vs. Post-test & 1 & 1.23 & 0.2683 \\
& Interaction & 1 & 0.81 & 0.3678 \\
\multirow{5}{*}{ Gender } & Male vs. Female & 1 & 0.03 & 0.8643 \\
& Pre-test vs. Post-test & 1 & 1.38 & 0.2403 \\
& Interaction & 1 & 0.81 & 0.3684 \\
\multirow{2}{*}{ Exposure } & Yes vs. No & 1 & 12.58 & 0.0004 \\
& Pre-test vs. Post-test & 1 & 1.42 & 0.2333 \\
& Interaction & 1 & 0.84 & 0.3616 \\
\hline
\end{tabular}

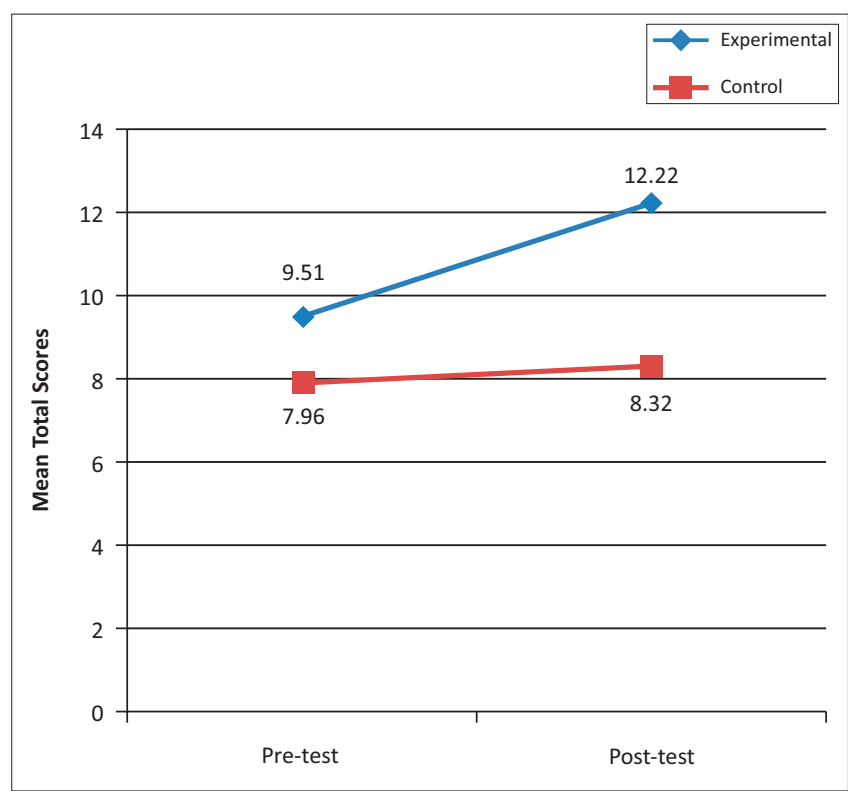

FIGURE 1: Pre-test and post-test scores experimental and control group.

significant higher average total score than the control group $(F(d f=1)=4.34 ; p=0.0379)$. The significance level was set at $\alpha=0.05$, which represents a confidence level of $95 \%$. The average total score of the experimental group was $\chi=9.51(\sigma=14.10)$, whilst that of the control group was $\chi=7.96(\sigma=11.96)$. Based on this result, it can be inferred that the experimental group began with more positive attitudes towards CWS than the control group pre-intervention. The high standard deviations in both groups, however, indicate that individual total scores were spread over a large range. In the experimental group, total scores ranged from -25 to 40 ; in the control group, the range was from -32 to 34 .

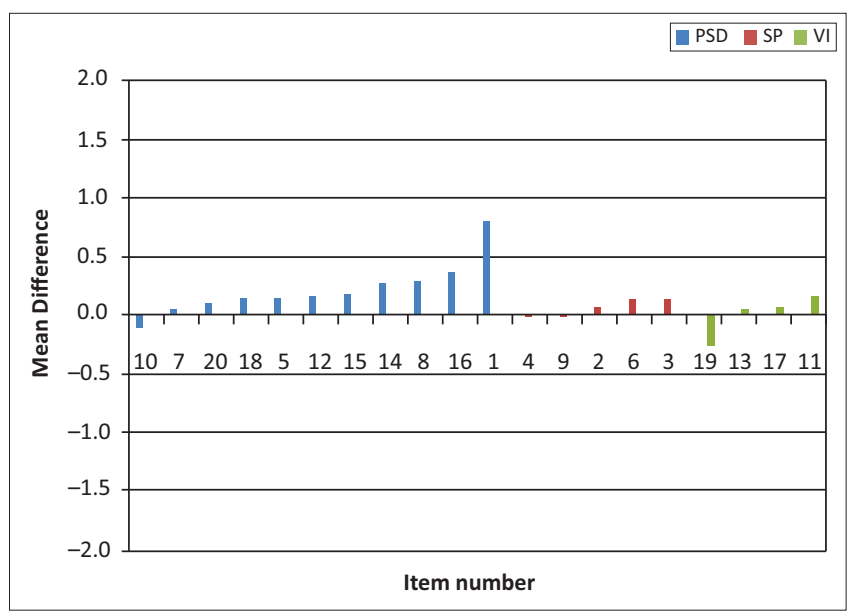

FIGURE 2: Mean shift in item average total scores of the subscales of the SROM between pre-test and post-test: experimental group.

In the post-test the experimental group again had a statistically significant higher average total score than the control group (see Table 2). The average total score of the experimental group was $\chi=12.22(\sigma=13.42)$, whilst that of the control group was $\chi=8.32(\sigma=13.95)$.

Within the experimental group, there was a higher post-test average total score than pre-test, reflecting a shift in scores in a positive direction. However, the magnitude of the shift was not found to be statistically significant $(F($ d.f. $=1)=1.23$; $p=0.2683 ; \alpha=0.05)$. Nonetheless, the pre-test average total score $(\chi=9.51, \sigma=14.10)$ increased by 2.71 to an average total score of $\chi=12.22(\sigma=13.42)$ during the post-test period.

In the control group there was no statistically significant change between the pre-test and post-test scores (see Table 2). Although the average total score during the pre-test period $(\chi=7.96, \sigma=11.96)$ increased to $\chi=8.32(\sigma=13.95)$ during the post-test period, this increase was minimal (mean shift $=$ 0.36 ) and not found to be statistically significant.

Given that the results of the experimental group changed from pre-test to post-test scores whilst that of the control group did not change significantly, it can be inferred that the intervention had a positive effect but not a significant effect one-month post-intervention (see Figure 2).

The mean shift scores from pre-test to post-test for the experimental group indicated that the shift occurred 


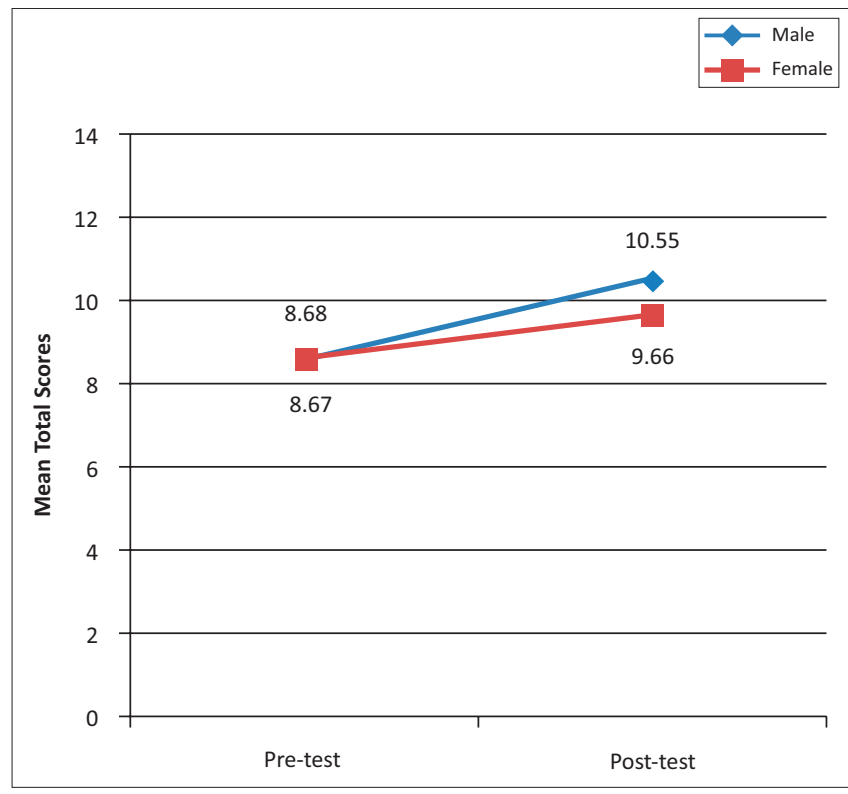

FIGURE 3: Pre-test and post-test scores for male and female participants.

predominantly in the positive social distance subscale compared to the verbal interaction and social pressure subscales (see Figure 3).

\section{Gender effect}

In the pre-test scores, there was no difference in attitude between males and females (see pre-test gender means, Table 1). In the post-test period, males showed a slightly greater positive shift in attitude than females. However, this difference was not found to be statistically significant $(F(d f=1)=0.03 ; p=0.8643 ; \alpha=0.05)$. Post-intervention, males had an average total score of $\chi=10.55(\sigma=13.97)$, whilst the average total score for females was $\chi=9.66(\sigma=13.71)$. The standard deviations for both males and females post-test indicate that there was individual variation in each of these groups. Nonetheless, these results indicate that gender did not have a significant effect on participants' attitudes towards CWS (see Figure 4).

\section{Exposure to stuttering}

On the SROM pre-test, participants who were previously exposed to stuttering had more positive scores than participants with no exposure $(F(d f=1)=12.58$; $p=0.0004$; $\alpha=0.05)$. The average total score for participants with exposure during pre-test was $\chi=9.62(\sigma=13.23)$, whilst that of participants with no exposure was $\chi=5.07(\sigma=11.42)$. During the post-test, this trend did not change; participants with previous exposure continued to show a statistically significant more positive scores than those without previous exposure (see Table 2). In addition, post-test results showed that scores for participants with exposure were higher than during pre-test, whilst those in participants without exposure remained the same post-intervention. Whilst the average total score of participants with exposure increased to $\chi=11.47(\sigma=13.71)$ post-intervention, that of participants without exposure decreased slightly to $\chi=4.95(\sigma=13.09)$

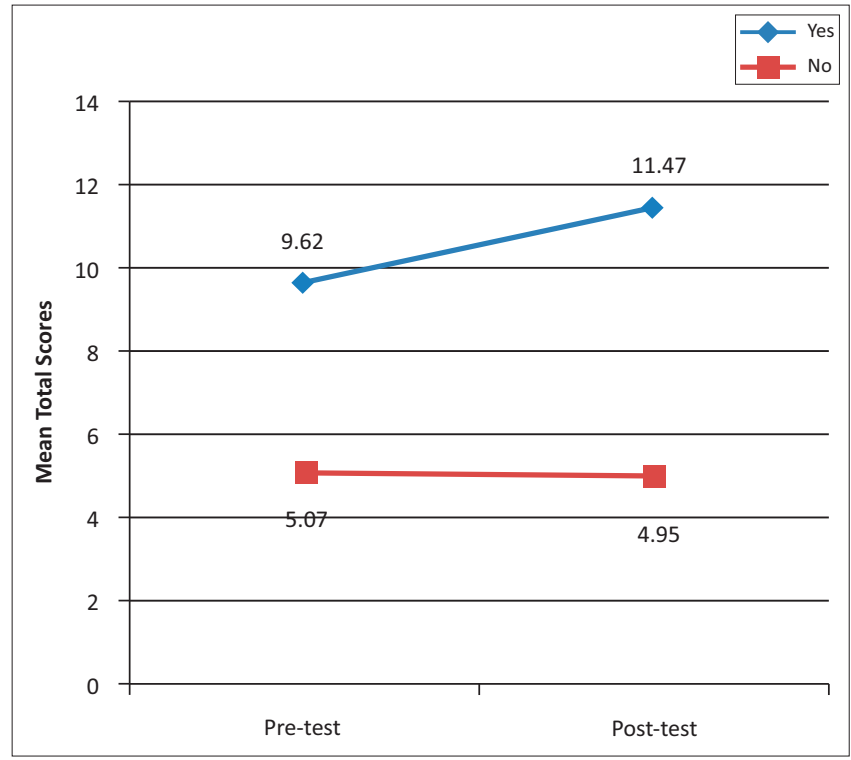

FIGURE 4: Pre-test and post-test scores for participants who had exposure/no exposure to stuttering.

post-intervention. Overall, results indicated that previous exposure to individuals who stutter has a positive effect on participants' attitude towards CWS during both pre-test and post-test and that the intervention has a positive impact on the previously exposed group compared with the group that had no exposure at one month post-intervention.

\section{Discussion}

\section{Treatment effect}

The results indicated positive scores in participants in the experimental group pre-intervention as compared to the control group. This difference may have occurred, as participants from the experimental group were from a different school than those of the control group. Although these schools were from similar areas in Cape Town, schools themselves are likely to be different and therefore may display varied attitudes. For example, schools may vary in the emphasis they place on issues of teasing and bullying. The strength of randomisation in the research design is that it is aimed at ensuring that each participant has an equal chance of being in experimental or control groups, thereby reducing the selection bias (Lindegger, 2006).

Groups also differed from each other post-intervention, with the experimental group again showing statistically significant more positive scores than the control group. Within the experimental group, the difference in average total scores between the pre-test and post-test period was 2.71. Although this difference was not found to be statistically significant with regard to the magnitude of the shift, the CCR appears to influence the change in attitudes in a positive direction. Overall, standard deviations were high in the experimental and control groups, indicating variation amongst participants.

The treatment effect may have been influenced by the time period. The post-test administration of the SROM occurred 
one month after the intervention of the CCR. Although Langevin and Prasad (2012) found a statistically significant difference in attitude over the same time period (i.e. 3-4 weeks), their intervention was more intensive than the CCR. The TAB intervention was provided on six occasions within the time period, as opposed to the current study which only provided an intervention on one occasion, i.e. a single dose of the intervention. Other research conducted by the National Disability Authority (2006) suggests that this time period may be too short to effect statistically significant attitude change. Attitude changes usually occur over longer periods of time and can take up to a few years. The results of the current study suggest that an attitude shift is beginning to occur in the experimental group. More time may be necessary to observe a greater shift in positive attitudes towards CWS. A follow-up study aiming to investigate the influence of the intervention after a six month interval may show further trends in attitude changes.

The sample size of the experimental group may have been too small to observe a significant difference in attitude in this study. The experimental group in this study consisted of 97 participants. The Langevin and Prasad study (2012) observed significant effects on a sample of 608 participants. A larger sample size in an RCT may therefore be helpful in observing changes with greater clarity.

The results of the subscale analysis may also help to understand which aspects of attitude shifts occurred postintervention. The subscale 'Positive Social Distance (PSD)' showed the greatest positive shift compared to the social pressure and verbal interaction subscales. Items from the PSD subscale, for example ('I would like having a child who stutters live next door to me') refers to neighbourly relations, which may indicate that the CCR has begun to effect attitude change amongst peripheral relations. The same can be argued for 'I would let a child who stutters hang out with us' - as PSD is linked to how comfortable the peer is around a CWS (Langevin et al., 2009). The intervention appeared to have a positive impact on social acceptance.

The other two subscales showed less positive shifts after intervention. 'Social pressure (SP)' showed limited improvement and a slight negative shift in items such as 'I would not go to the shop with a child who stutters.' SP is linked to how one feels about what other peers think about CWS (Langevin et al., 2009). The 'verbal interaction (VI)' subscale showed the least positive shift in attitudes overall. VI reflects feeling of frustration when communicating with CWS, for example 'Children who stutter should not play games that involve talking' (Langevin et al., 2009). The results at this stage of the study suggested that the CCR brought positive shifts in social acceptance of participants but not yet in levels of frustration during communication with CWS.

Since the shift in the experimental group is comparatively larger than that of the control group, the positive shift may possibly be attributed to the effects of the CCR on the experimental group. This result was consistent with findings by Langevin and Prasad (2012) which showed that participants had more positive attitudes towards CWS following the implementation of TAB intervention. However, before an RCT is considered, the results of the six-month postintervention measure should be considered. Particularly, the negative effect must be monitored carefully, as raising awareness could also have negative effects if not managed carefully.

\section{Exposure}

The results indicated that exposure to stuttering has an effect on peers' attitude towards CWS; a statistically significant more positive attitude towards CWS was noted in participants with previous exposure. The literature points towards a positive effect of exposure on attitudes. Children who have been exposed to stuttering may have a greater sense of empathy and understanding of CWS (Wiesel \& Spektor, 1998). This would positively affect their perception and attitudes towards CWS. The higher post-test score for participants with exposure may indicate the potential of the CCR to improve existing positive attitudes.

No change was observed between pre-test and post-test for those with no previous exposure. This result may indicate that a longer time period may be necessary to effect attitude change in individuals who have not been exposed to this communication disorder. Contrary to this study, Langevin and Prasad (2012) found that children who did not know someone who stutters had higher change scores on their outcome measure compared to those exposed to stuttering. They suggested that the TAB could mobilise children who have not had previous exposure to stuttering to support their peers who stutter. Although no changes were noted in the current study in participants with previous exposure to stuttering, the CCR may still be a tool to increase awareness of CWS and reduce associated teasing and bullying. The results of this study point to the need for a closer examination of exposure to stuttering at 6 months post-intervention.

\section{Gender}

Results indicated that gender did not have an effect on peers' attitude towards CWS. The study by Langevin and Prasad (2012) showed no significant effect of gender on peer attitudes towards CWS. The results of the current study are consistent with this last finding, indicating that gender may not be a factor that influences attitudes towards CWS. Therefore, it may not be a variable to pursue in a further study unless the observation changes at 6 months post-intervention.

\section{Limitations of the study}

After completing this segment of the study, some limitations were brought to light. The main limitations include:

- The SROM being the only measure of attitude change.

- Participants were of diverse linguistic backgrounds and had varied English language proficiency, which might 
affect their performance on the SROM. Although the researchers took all available steps to ensure that the items were understood, this factor remains an area of concern.

- The sample size in the experimental group was smaller than the experimental group due to absenteeism which was beyond the control of the study.

\section{Clinical implications}

The findings of this study point to the potential effect of the CCR as an intervention which can facilitate positive attitude change. The study raises awareness of the importance of a focus on changing negative attitudes of peers towards CWS, in South Africa. Whilst clinicians commonly work on an individual basis with children, their attention is directed to the impact of negative attitudes of peers. This intervention provides insights into classroom-based interventions as a possible strategy for intervention.

Furthermore, in a context like South Africa, as well as other contexts where under-resourcing is a common problem (Kathard \& Pillay, 2013), therapists can include teachers as intervention partners as a strategy to reduce negative attitudes towards peers who stutter.

The study also highlighted that participants who were exposed to children who stutter had more positive attitudes compared to their peers who were not exposed. Therefore, it is vitally important that therapists encourage children in classrooms to interact with CWS - in close proximity activities to facilitate exposure as a strategy to reduce negative attitudes.

\section{Recommendations for further research}

- As this was a small scale study which considered attitude changes at one month post-intervention, it is essential that attitudes changes in further studies are considered over a longer term period in lower quintile schools. A further study examines attitude changes in higher quintile schools (Walters, 2014).

- A further large-scale study must consider cluster effect to determine the appropriate size of the sample of a future RCT. It is envisaged that further studies would require larger samples to accommodate the cluster effect.

- Further studies should seek to determine the clinical significance of findings. Whilst this study focused on the statistical significance, a further investigation could consider literature guidelines and clinician guidelines for what can be considered clinically significant results in classroom-based interventions such as the CCR.

\section{Conclusion}

The results in this study at one month post-intervention indicated a positive shift direction in treatment effect, indicating improved attitude towards CWS in participants of the experimental group as compared to the control group.
The magnitude of the attitude change was not statistically significant. Gender did not appear to influence participants' attitude towards CWS. Previous exposure to stuttering had a significant positive effect on participants' pre- and posttest attitudes to CWS. This study concluded that treatment effect of the CCR was small but positive at one month postintervention, warranting further study.

\section{Acknowledgements Competing interests}

The authors declare that they have no financial or personal relationship(s) that may have inappropriately influenced them in writing this article.

\section{Authors' contributions}

H.K. (University of Cape Town) was the primary investigator and first author. F.W. (University of Cape Town) and F.C-S. (University of Cape Town) contributed to the development of the study and are senior authors of this article. K.F. (University of Cape Town), T.M. (University of Cape Town), M.R. (University of Cape Town), R.S. (University of Cape Town), J.W. (University of Cape Town), N.Z. (University of Cape Town) and A.Z. (University of Cape Town) planned and executed the study and contributed actively to writing the article.

\section{References}

Badroodien, R., Bielovich, J., Lilienfeld, S., Naiker, P., Stevens, M., \& Weavind, J. (2011) Changes in peer attitudes towards children who stutter after the administration of a Classroom Communication Resource. Unpublished undergraduate thesis, University of Cape Town, South Africa.

Creswell, J. (2009). Research design: Qualitative, quantitative, and mixed methods approaches. Los Angeles: Sage.

De Freitas, S., Geben, C., Parusnath, P., Relleen, A., \& Van den Berg, N. (2012). Changes in negative peer attitudes towards children who stutter after the administration of a Classroom Communication Resource. Unpublished undergraduate thesis, University of Cape Town, South Africa.

De Grass, J., Gessesse, H., Harrison, J., Naidoo, L., Sewpersad, A., \& Vaggie, Z. (2010) Changes in peers' attitudes towards learners who stutter after the administration of a Classroom Communication Resource. Unpublished undergraduate thesis, University of Cape Town, South Africa.

Department of Education (2008). National norms and standards for school funding (NNSSF). Retrieved June 3, 2013, from http://www.info.gov.za/view/ DownloadFileAction?id=90952

Dietrich, S., Jensen, K.H., \& Williams, D.F. (2001). Effects of the label 'stutterer' on student perceptions. Journal of Fluency Disorders, 26, 55-66. http://dx.doi. org/10.1016/S0094-730X(00)00030-9

Evans, D., Healey, E.C., Kawai, N., \& Rowland, S. (2008). Middle school students' perceptions of a peer who stutters. Journal of Fluency Disorders, 33, 203-219. http://dx.doi.org/10.1016/j.jfludis.2008.06.002

Filies, S., Hartley, R., Kaplan, G.R., \& Pettit, L. (2009). Teachers' and learners' responses towards a classroom resource about communication and communication difficulties. Unpublished undergraduate thesis, University of Cape Town, South Africa.

Hughes, S. (2014). Bullying: What speech-language pathologists should know. A tutorial. Language, Speech and Hearing Services in Schools, 35, 3-13. http:// dx.doi.org/10.1044/2013_LSHSS-13-0013

Kathard, H. \& Pillay M. (2013). Promoting change through political consciousness. A South African speech-language pathology response to the World Report on Disability, International Journal of Speech-language Pathology, 15(1), 84-89. http://dx.doi.org/10.3109/17549507.2012.757803

Langevin, M. (1997). Peer teasing project. In E.C. Healey \& H.F.M. Peters (Eds.), Second World Congress on Fluency Disorders: Proceedings (pp. 169-171). The Netherlands: Nijmegen University Press.

Langevin, M. (2000). Teasing and bullying: Unacceptable behaviour (TAB). Alberta: Institute for Stuttering Treatment and Research.

Langevin, M. (2009). The peer attitudes toward children who stutter scale: Reliability, known group validity, and negativity of elementary school-age children's attitudes. Journal of Fluency Disorders, 34, 72-86. http://dx.doi.org/10.1016/j. jfludis.2009.05.001 
Langevin, M., \& Hagler, P. (2004). Development of a scale to measure peer attitudes towards children who stutter. In A.K. Bothe (Ed.), Evidence-based treatment of stuttering: Empirical bases and clinical applications (pp. 139-171). USA: Lawrence stuttering: Empirical bases and clinical applications (
Erlbaum Associates. (before Langevin and Prasad)

Langevin, M., Kleitman, S., Packman, A., \& Onslow, M. (2009). The peer attitudes toward children who stutter (PATCS) scale: An evaluation of validity, reliability and the negativity of attitudes. International Journal of Language \& Communication Disorders, 44, 352-368. http://dx.doi.org/10.1080/13682820802130533

Langevin, M., \& Prasad, N. (2012). A stuttering education and bullying awareness and prevention resource: A feasibility study. Language, Speech, and Hearing Services in Schools, 43, 344-358. http://dx.doi.org/10.1044/0161-1461(2012/11-0031)

Leedy, P.D., \& Ormrod, J.E. (2005). Practical research: Planning and design (8th edn.). New Jersey: Pearson Education.

Lenth, R.V. (2001). Some practical guidelines for effective sample size determination. American Statistical Association, 55, 187-193.

Liang, H., Flisher, A.J., \& Lombard, C.J. (2007). Bullying, violence, and risk behaviour in South African school students. Child Abuse \& Neglect, 31, 161-171. http://dx.doi. org/10.1016/j.chiabu.2006.08.007

Lindegger, G. (2006). Research methods in clinical research. In M. Terre Blanche, K. Durrheim \& D. Painter (Eds.), Research in practice: Applied methods for the K. Durrheim \& D. Painter (Eds.), Research in practice: Applied methods for the
social sciences (2nd edn.) (pp. 456-475). Cape Town: University of Cape Town social scie
Press.

Mestry, R., Van der Merwe, M. \& Squelch, J. (2006). Bystander behaviour of school children observing bullying. SA-eDUC Journal, 3, 46-59.

Murphy, W.P., \& Quesal, R.W. (2002). Strategies for addressing bullying with the school-age child who stutters. USA: Thieme Medical Publishers. http://dx.doi. org/10.1016/j.jfludis.2007.02.001

Murphy, W.P., Yaruss, J.S., \& Quesal, R.W. (2007). Enhancing treatment for school-age children who stutter II: Reducing bullying through role-playing and self-disclosure. Journal of Fluency Disorders, 32, 139-162.
National Disability Authority (2006). Literature review on attitudes towards disability. Retrieved June 4, 2013, from http://www.ucd.ie/issda/static/documentation/ nda/nda-literature-review.pdf

Panik, M. (2005). Advanced statistics from an elementary point of view. U.S.A.: Academic Press.

Parker, J.G., \& Asher, S.R. (1993). Friendship and friendship quality in middle childhood: Links with peer group acceptance and feelings of loneliness and social dissatisfaction. Developmental Psychology, 29, 611-621. http://dx.doi. org/10.1037/0012-1649.29.4.611

St. Louis, K.O. (2012). Male versus female attitudes toward stuttering. Journal of Communication Disorders, 45, 246-253.

Thabane, L., Ma, J., Chu, R., Cheng, J., Ismaila, A., Rios, L. et al. (2010). A tutorial on pilot studies: the what, why and how. BMC Medical Research Methodology 2010, 10:1 http://www.biomedcentral.com/1471-2288/10/1

Turnbull, J. (2006). Promoting greater understanding in peers of children who stammer. Emotional and Behavioural Difficulties, 11, 237-247. http://dx.doi. org/10.1080/13632750601022139

Walters, F. (2014). Changes in peers' attitudes towards children who stutter after the administration of the Classroom Communication Resources.Masters in progress. University of Cape Town, South Africa.

Whitehead, D. (2001). Health education, behavioural change and social psychology: Nursing's contribution to health promotion?. Journal of Advanced Nursing, 34, Nursing's contribution to health promotion?. Journal of Advance
822 -832. http://dx.doi.org/10.1046/j.1365-2648.2001.01813.x

Wiesel, A., \& Spektor, G. (1998). A possible explanation of the "stutterer" stereotype. Journal of Fluency Disorders, 23, 157-172.

Williams, J.R. (2008). The Declaration of Helsinki and public health. Bulletin of the World Health Organization, 86, 650-652. http://dx.doi.org/10.2471/BLT.08.050955

Yaruss, J.S. (2007). Application of the ICF in fluency disorders. Seminars in Speech and Language, 28, 312-322. http://dx.doi.org/10.1055/s-2007-986528 


\section{Appendix: A}

The items of the SROM according to subscales

\begin{tabular}{|c|c|c|c|c|}
\hline \multirow[t]{2}{*}{ Item Number } & \multirow[t]{2}{*}{ Item } & \multicolumn{3}{|c|}{ Subscale } \\
\hline & & PSD & SP & VI \\
\hline 1. & I would like having a child who stutters live next door to me. & PSD & - & - \\
\hline 5. & I would enjoy doing a class project with a child who stutters. & PSD & - & - \\
\hline 7. & I would introduce a child who stutters to my friends. & PSD & - & - \\
\hline 8. & I would be happy to have a child who stutters for a friend. & PSD & - & - \\
\hline 10. & In class I would like to sit next to a child who stutters. & PSD & - & - \\
\hline 12. & I would like a child who stutters to talk for my group in class. & PSD & - & - \\
\hline 14. & I would let a child who stutters hang out with us. & PSD & - & - \\
\hline 15. & I would enjoy being with a child who stutters. & PSD & - & - \\
\hline 16. & I would be best friends with a child who stutters. & PSD & - & - \\
\hline 18. & I would like having a child who stutters in my class. & PSD & - & - \\
\hline 20. & I would spend time at break with a child who stutters. & PSD & - & - \\
\hline 2. & I would avoid a child who stutters. & - & SP & - \\
\hline 3. & Children who stutter are like normal children. & - & SP & - \\
\hline 4. & I would be ashamed to be seen with a child who stutters. & - & SP & - \\
\hline 6. & Children who stutter are weird. & - & SP & - \\
\hline 9. & I would not go to the shop with a child who stutters. & - & SP & - \\
\hline 11. & I would be frustrated listening to a child who stutters. & - & - & $\mathrm{VI}$ \\
\hline 13. & Listening to a child who stutters would annoy me. & - & - & $\mathrm{VI}$ \\
\hline 17. & I would be embarrassed to be with a child who stutters. & - & - & $\mathrm{VI}$ \\
\hline 19. & Children who stutter should not play games that involve talking. & - & - & $\mathrm{VI}$ \\
\hline
\end{tabular}

$\mathrm{PSD}$, positive social distance; SP, social pressure; $\mathrm{VI}$, verbal interaction. 


\section{Appendix B:}

Flowchart - Procedure

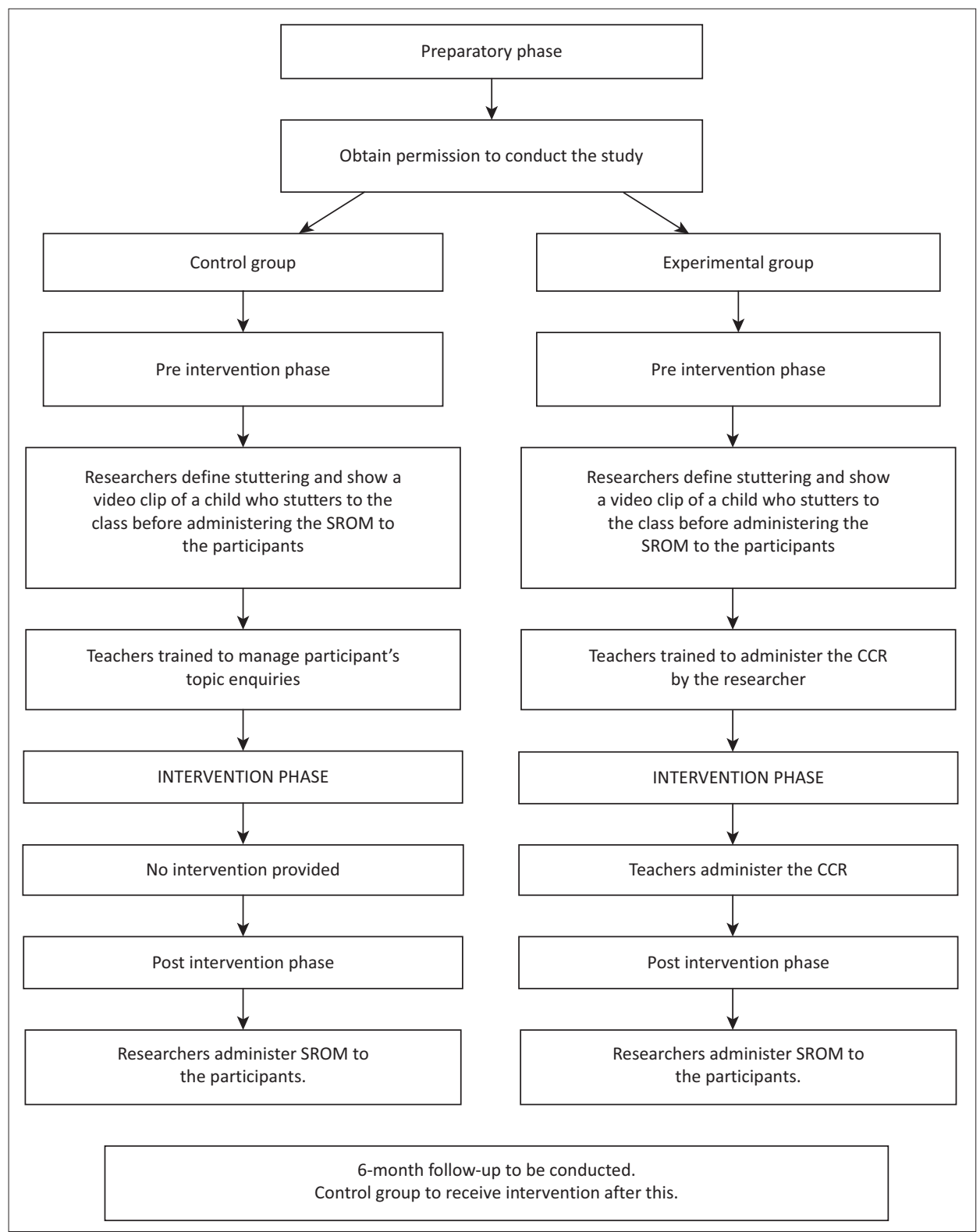

